\title{
Combining Helium Collision Mode, Aerosol Dilution and Discrete Sampling to Maximize Matrix Tolerance and Productivity in ICP-MS Analysis of Environmental Samples
}

\author{
Steven M. Wilbur ${ }^{*}, 1$ and L. Craig Jones ${ }^{2}$ \\ ${ }^{I}$ Agilent Technologies, Inc., $161575^{\text {th }}$ Street SW Suite 210, Everett, Washington 98203-6261, USA \\ ${ }^{2}$ Agilent Technologies, Inc., 5301 Stevens Creek Blvd, Santa Clara, CA 95051-7201, USA
}

\begin{abstract}
By combining recent advances in inductively coupled plasma mass spectrometry (ICP-MS) technology including improved collision cell efficiency, aerosol dilution and discrete sampling, a rare synergy has been achieved resulting in a system that is not only much faster than previous instruments, but also shows improved ease of use and superior matrix tolerance. This work demonstrates the benefits of such a system by demonstrating United States Environmental Protection Agency (USEPA) compliant analysis of a range of high matrix certified reference materials for 26 elements in less than 2 minutes per sample.
\end{abstract}

Keywords: ICP-MS, discrete sampling, high matrix, collision cell, HMI, high throughput.

\section{INTRODUCTION}

With the advent of helium mode collision cell inductively ICP-MS and the more recent introduction of online aerosol dilution (High Matrix Introduction (HMI) system - Agilent Technologies, Tokyo, Japan), robust, accurate analysis of complex, high matrix samples such as soils and sludges has become routine $[1,2]$. However, increasing competition and financial pressure has led to greater focus on productivity in contract with environmental laboratories [3]. At the same time, it is essential that data quality and ease of use should not compromised. Discrete sampling, also known as flow injection, offers a solution to the need for increased productivity, with the additional benefits of improved matrix tolerance and long term stability [4, 5]. In fact, matrix tolerance and high productivity in ICP-MS are two sides of the same coin. Enhancements which improve matrix tolerance inherently improve productivity by minimizing dilutions, reruns and maintenance; and productivity enhancements which reduce sample analysis time increase matrix tolerance by minimizing exposure of the instrument to matrix components. From a practical standpoint, high productivity has two components; 1- run time or rate in samples per hour, and 2 - robustness or reliability, which translates into how many hours the system can run at a given rate.

Helium collision mode, aerosol dilution and discrete sampling can work together to improve the overall productivity of an ICP-MS system. Run time, the first component of productivity can be subdivided into several subcomponents; sample uptake time, stabilization time, sample analysis time, washout time and overhead including

*Address correspondence to this author at the Agilent Technologies, Inc., $161575^{\text {th }}$ Street SW Suite 210, Everett, Washington 98203-6261, USA;

Tel: +1-425-356-6333; Fax: +1-360-468-3683;

E-mail: steven.wilbur@agilent.com autosampler movement and data processing time. Discrete sampling can significantly reduce sample uptake and washout time when compared to systems using traditional peristaltic pump sample uptake systems. Traditional peristaltic pump uptake systems (Fig. 1, left) cannot uncouple the nebulizer flow during analysis from the uptake and rinseout flows. Since uptake and rinseout are typically performed at high flow, additional time is necessary for the analyte signal to stabilize after the flow is reduced to the optimum flow for analysis. Additionally, uptake, analysis and rinseout must happen sequentially. A typical 5 minute run profile is shown in Fig. (1, bottom right). During the 5 minute run, as much as $5-10 \mathrm{ml}$ of sample is consumed, all of it passing through the nebulizer and into the ICP-MS, contributing to salt accumulation on the interface components which can cause instability and gradual loss of sensitivity. In contrast, a typical discrete sampling system is shown in Fig. (2a, b).

The discrete sampling system consists of a 6-port valve with a sample loop, a high speed uptake pump (ISIS P1) to pull the sample into the loop, and a constant speed nebulizer pump (P2) to flush the sample from the loop to the nebulizer while also adding the internal standard online. When the valve is in the "load" position (Fig. 2a, left), the uptake pump (ISIS P1) rapidly draws the sample from the sample vial through the loop and directs the excess to waste. The uptake system is quickly rinsed with the sample while the loop is filled. At the same time, the nebulizer pump (P2) is slowly pumping clean carrier solution to the nebulizer, rinsing the downstream half of the system. After the loop is filled, the valve rotates to the inject position, placing the loop in the carrier flow path (Fig. 2b, right). The carrier flow now pushes the sample from the loop to the nebulizer without disturbing the constant, optimum nebulizer flow. As a result, the need for stabilization time is eliminated. Additionally, once the valve has rotated to the inject position, the sample uptake tubing is isolated from the nebulizer and the 


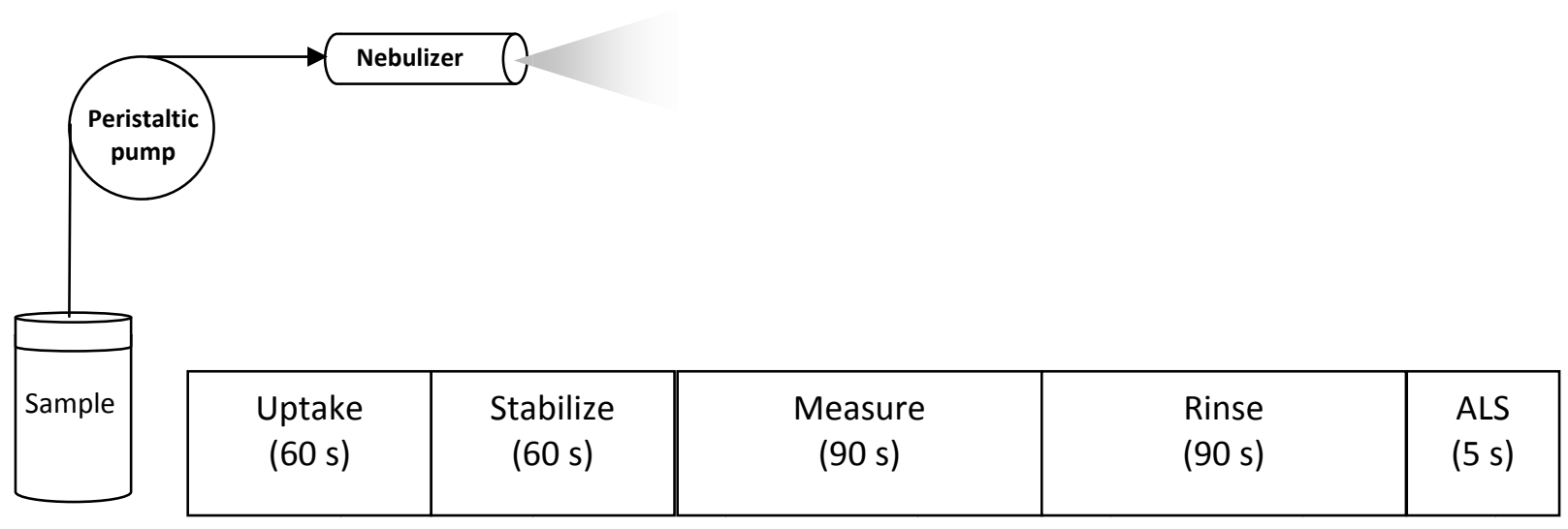

Fig. (1). Schematic flow diagram of conventional direct peristaltic pumped sample uptake system in ICP-MS (left). Typical time for each sequential step in sample analysis is indicated in the box diagram at the bottom right. ALS - Automated liquid sampler.

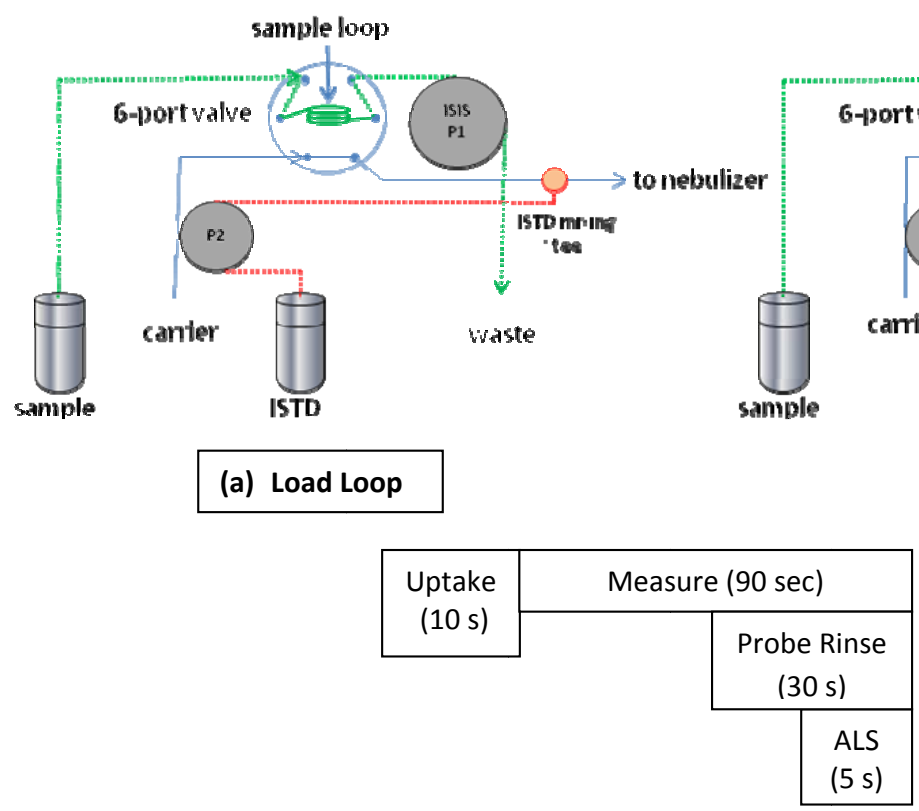

Fig. (2). Schematic diagram of sample flow using discrete sampling in ICP-MS (top left and right). Typical time for each step in the analysis is indicated in the box diagram at the bottom left. Since the sample probe rinse and ALS overhead occur simultaneously with analysis, they are shown in parallel rather than sequentially.

autosampler probe can move to the rinse position or next sample position and begin preparing for the next analysis. The analysis profile is shown in Fig. (2, bottom). Because sample uptake is isolated from the nebulizer, it can be at a much higher flow rate than conventional systems, and therefore much faster. This high uptake flow also serves to rinse the entire sample path using the sample itself, which reduces or eliminates the need for a separate rinse step. Carryover from sample to sample via the sample probe is eliminated by moving the probe to a rinse position during analysis, which adds no additional time to the run. Thus a typical run time of 5 minutes can be reduced to less than 2 minutes through the use of discrete sampling even though the actual measurement time remains unchanged.
By using helium collision mode as the single collision cell mode, the actual measurement time can be significantly reduced when compared to collision/reaction cells (CRCs) that must use more than one cell gas or cell mode in order to effectively remove all polyatomic interferences. Helium mode uses a process known as kinetic energy discrimination (KED), which removes polyatomic interferences based on their larger collisional cross section when compared with atomic ions $[6,7]$. As a result of their larger size, polyatomic ions undergo more collisions in the cell and lose more kinetic energy. A positive voltage bias at the exit of the cell prevents the low energy polyatomic ions from entering the quadrupole, while allowing the more energetic atomic ions to freely pass. Helium is both inert and low in mass so it 
does not cause unwanted reactions which could form new interferences or reduce sensitivity by reacting with analyte elements, nor does it cause excessive scattering of lower mass analyte ions as a heavier inert gas would. Because of these traits, helium mode can be used as the only cell mode for environmental analysis, eliminating the need for time consuming cell gas changes and associated stabilization times [8].

The third leg of the productivity triad, aerosol dilution, plays a critical yet less direct role. Aerosol dilution is the process whereby the sample aerosol is mixed with flowing argon between the spray chamber and torch, effectively diluting the density of the sample aerosol before it enters the plasma (Fig. 3). Aerosol dilution achieves two goals. It effectively dilutes high matrix samples without the need for either manual or automatic liquid dilutions which can take time and introduce contamination. More importantly, because the diluent is a gas, the aerosol entering the plasma contains much less water (and acid) than a conventionally diluted sample, resulting in much hotter plasma and as much as ten times lower oxide formation. As a result, aerosol dilution reduces the need for conventional dilution of out of range samples, minimizes internal standard failures and required re-runs due to matrix-induced signal suppression, and increases the interval between cone and lens cleaning. It also improves long term stability as evidenced both by raw internal standard response and continuing calibration verification $(\mathrm{CCV})$ checks, thereby increasing the number of hours the system can run at a high sample rate.

\section{EXPERIMENTAL}

An Agilent 7700x ICP-MS (Agilent Technologies, Tokyo Japan) fitted with standard glass concentric nebulizer, quartz double-pass spraychamber and nickel sampler and skimmer cones was used. The $7700 x$ can operate the collision cell in either no gas mode or helium collision mode. In this work, only He mode was used. The integrated HMI aerosol dilution system was used for this work. The HMI was set for ultra robust plasma conditions $\left(\mathrm{CeO}^{+} / \mathrm{Ce}^{+}\right.$ratio $\left.<0.2 \%\right)$ and approximately 1:2 aerosol dilution factor. The system was also fitted with the optional Integrated Sample Introduction System-Discrete Sampling (ISIS-DS) (Agilent Technologies, Tokyo, Japan) system for discrete sampling. Instrument operating parameters are shown in Table 1. See Fig. (2) for details of the ISIS-DS configuration.

Accuracy, productivity and long term stability were tested by analyzing a long sequence consisting of water, soil, and sediment Standard Reference Materials (SRMs), as well as spiked seawater samples and associated Quality Control (QC) samples required by USEPA method 6020A to simulate a typical sample load in a contract environmental laboratory (Fig. 4). Calibration standards were prepared in a $1 \% \mathrm{HNO}_{3} / 0.5 \% \mathrm{HCl}$ matrix. The addition of $\mathrm{HCl}$ to the samples and calibrators insures stability of otherwise difficult elements such as $\mathrm{Ag}, \mathrm{Hg}$ and $\mathrm{Sb}$. No matrix matching was required and no recalibrations were performed. Since the goal was to obtain the highest possible productivity while meeting USEPA requirements for quality control and maintaining sensitivity sufficient for typical environmental analysis, integration times for each element were kept as short as possible. A single point per peak was acquired, with integration times of typically 0.1 to $0.3 \mathrm{sec}$ per element; $\mathrm{Be}(1.0$ second $)$ and $\mathrm{Hg}(1.5 \mathrm{sec})$ were given longer integration times to compensate for the relatively lower response of $\mathrm{Be}$ in $\mathrm{He}$ mode and the need for a very low method detection limit (MDL) for $\mathrm{Hg}$ [9]. Three replicates of each acquisition were performed to comply with USEPA requirements.

Table 1. ICP-MS (7700x) and Discrete Sampling System (ISIS-DS) Parameters Used

\begin{tabular}{|c|c|}
\hline \multicolumn{2}{|c|}{ 7700x ICP-MS Parameters } \\
\hline \hline RF Power (W) & 1550 \\
\hline Carrier Gas Flow (L/min) & 0.5 \\
\hline Dilution Gas Flow (L/min) & 0.5 \\
\hline Extract 1 (V) & 0 \\
\hline Cell Gas/Flow & He/2.3 mL/min \\
\hline Kinetic Energy Discrimination (V) & 10.0 \\
\hline Number of Elements/Internal Standards & 26 analytes, 6 ISTDs \\
\hline Total Acquisition Time (3 reps) & 63 seconds \\
\hline ISIS-DS Discrete Sampling Parameters \\
\hline \hline Loop volume & $600 \mu \mathrm{L}$ \\
\hline Uptake time & 10 seconds \\
\hline Acquisition Delay & 25 seconds \\
\hline Rinse Time & Pre-emptive rinse during \\
acquisition
\end{tabular}

\section{RESULTS AND DISCUSSION}

Actual integration times and calculated method detection limits (MDL) are shown in Table 2. MDLs were calculated as 3.14 times the standard deviation of 7 replicates of the low calibration standard. Note that these are not "best possible" detection limits but are more than sufficient for the method

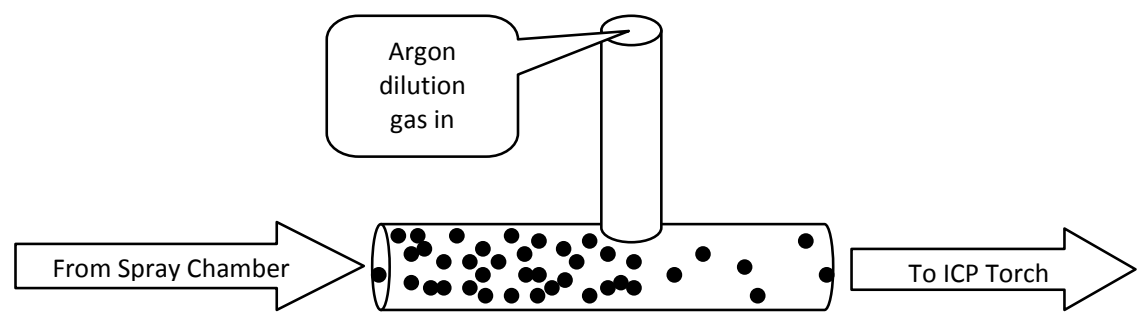

Fig. (3). Diagram of aerosol dilution system. Dense aerosol enters transfer tube from spray chamber. Argon gas is added, decreasing aerosol density before entering ICP torch. 

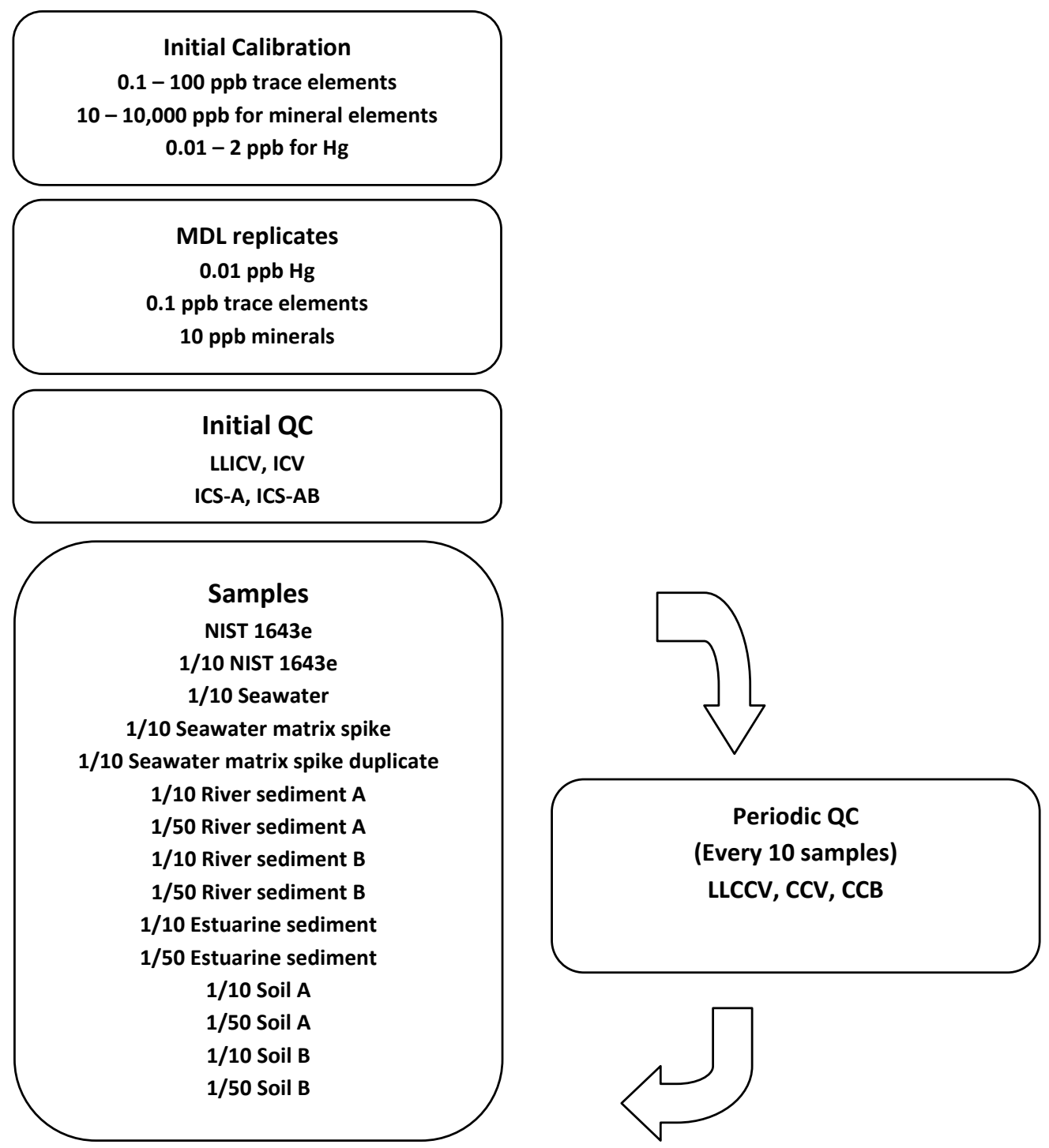

Fig. (4). Sequence of samples analyzed in a single 8-hour sequence. Sample Block was repeated continuously with automatic insertion of Periodic QC Block after each 10 sample runs. Number of analyses in 8 hours totaled 275.

requirements. Lower detection limits would require significantly more effort in reducing blank contamination, with a commensurate increase in time and cost of analysis.

\subsection{Meeting USEPA QA/QC Requirements}

USEPA method $6020 \mathrm{~A}$ is a performance based method and consequently, unlike method 200.8 for drinking water analysis, USEPA has not restricted the use of collision/reaction cell technology for method 6020 applications. The most recent version of USEPA 6020A (Feb 2007) has added the requirement for a Low Level Initial Calibration Verification (LLICV) check at approximately the method reporting limit. The recommended control limits are $\pm 30 \%$ of the actual value. The results for the LLICV are shown in Table 3. These results confirm sub ppb reporting limits for all trace elements and reporting limits in the 10-50 ppb range for the mineral elements. Reducing laboratory contamination for the mineral elements would allow lower reporting limits if required.
In addition to calculating and verifying MDLs and reporting limits, method $6020 \mathrm{~A}$ requires that internal standard (ISTD) recoveries for all samples exceed $70 \%$ of the ISTD response in the calibration blank. Continuing Calibration Verification (CCV) samples at the midpoint concentration of the calibration must be analyzed after each 10 real samples and must recover within $\pm 10 \%$ of the true value. If either of these criteria is not met, the affected samples must be re-analyzed, either after dilution in the case of ISTD failure, or after recalibration in the case of CCV failure. CCV recoveries for all $19 \mathrm{CCV}$ replicates run over the course of the sequence are shown in Fig. (5). Only sodium exceeded the $+10 \%$ limit towards the end of the sequence, as a result of gradual cross contamination from repeated seawater analysis. Internal standard recoveries are shown in Fig. (6). The flat slope of the ISTD curve indicates that there was no loss in sensitivity due to matrix accumulation on the interface or lenses for the entire sequence. In addition, there were no internal standard 
Table 2. Integration Times and Calculated Method Detection Limits (MDL) for Each of 26 Analyte Elements. Numbers Before the Element Name Indicate the Isotope Measured for that Element

\begin{tabular}{|c|c|c|c|c|c|}
\hline Isotope/Element & Integration Time (Sec) & 3 Sigma MDL $(\mu \mathrm{g} / \mathrm{L})$ & Isotope/Element & Integration Time (Sec) & 3 Sigma MDL $(\mu \mathrm{g} / \mathrm{L})$ \\
\hline $9 \mathrm{Be}$ & 1.0 & 0.040 & $66 \mathrm{Zn}$ & 0.3 & 0.058 \\
\hline $24 \mathrm{Mg}$ & 0.1 & 1.622 & $78 \mathrm{Se}$ & 1.5 & 0.386 \\
\hline $27 \mathrm{Al}$ & 0.1 & 1.674 & $95 \mathrm{Mo}$ & 0.3 & 0.062 \\
\hline $44 \mathrm{Ca}$ & 0.1 & 7.784 & $111 \mathrm{Cd}$ & 0.3 & 0.033 \\
\hline $51 \mathrm{~V}$ & 0.3 & 0.037 & $121 \mathrm{Sb}$ & 0.3 & 0.051 \\
\hline $52 \mathrm{Cr}$ & 0.3 & 0.034 & $137 \mathrm{Ba}$ & 0.3 & 0.048 \\
\hline $55 \mathrm{Mn}$ & 0.3 & 0.033 & $201 \mathrm{Hg}$ & 1.5 & 0.006 \\
\hline $63 \mathrm{Cu}$ & 0.3 & 0.028 & $238 \mathrm{U}$ & 0.1 & 0.011 \\
\hline
\end{tabular}

failures in any sample, which demonstrates the exceptional matrix tolerance delivered by the 7700x system with HMI.

Table 3. Low Level Initial Calibration Verification (LLICV) Recoveries. Column 2 is LLICV Concentration, Column 3 is Percent Recovery Relative to Actual Concentration. USEPA Limits are $\pm 30 \%$ of Expected

\begin{tabular}{|c|c|c|}
\hline Isotope/Element & {$[\mathrm{LLICV}](\mu \mathrm{g} / \mathrm{L})$} & Recovery (\%) \\
\hline $9 \mathrm{Be}$ & 0.10 & 96 \\
\hline $23 \mathrm{Na}$ & 50.00 & 89 \\
\hline $24 \mathrm{Mg}$ & 10.00 & 97 \\
\hline $39 \mathrm{~K}$ & 50.00 & 103 \\
\hline $44 \mathrm{Ca}$ & 50.00 & 93 \\
\hline $51 \mathrm{~V}$ & 0.10 & 101 \\
\hline $52 \mathrm{Cr}$ & 0.10 & 101 \\
\hline $55 \mathrm{Mn}$ & 0.20 & 102 \\
\hline $56 \mathrm{Fe}$ & 0.20 & 92 \\
\hline $59 \mathrm{Co}$ & 0.20 & 101 \\
\hline $60 \mathrm{Ni}$ & 0.20 & 97 \\
\hline $63 \mathrm{Cu}$ & 0.20 & 100 \\
\hline $66 \mathrm{Zn}$ & 0.50 & 102 \\
\hline $75 \mathrm{As}$ & 0.10 & 97 \\
\hline $78 \mathrm{Se}$ & 0.50 & 121 \\
\hline $107 \mathrm{Ag}$ & 0.10 & 96 \\
\hline $121 \mathrm{Sb}$ & 0.10 & 81 \\
\hline $201 \mathrm{Hg}$ & 0.10 & 92 \\
\hline $208 \mathrm{~Pb}$ & 0.20 & 103 \\
\hline $232 \mathrm{Th}$ & 0.50 & 103 \\
\hline $238 \mathrm{U}$ & 0.02 & 104 \\
\hline
\end{tabular}

\subsection{Seawater Matrix Spike and Matrix Spike Duplicates}

Synthetic $1 / 10$ seawater $(0.3 \%$ high purity $\mathrm{NaCl}$, SPEX Certiprep, Metuchen NJ, USA) was analyzed periodically along with seawater Matrix Spike (MS) and Matrix Spike Duplicates (MSD) spiked at $1 \mathrm{ppb}$ for trace elements and 100 ppb for mineral elements $(\mathrm{Mg}, \mathrm{K}, \mathrm{Ca}$ and $\mathrm{Fe})$. The number of repeats of each of these sample types was 10 , interspersed with the other samples throughout the sequence. No matrix matching of the calibration standards and blanks to the $10 \%$ seawater samples was required, as HMI effectively eliminates matrix suppression by ensuring very high temperature plasma conditions (around $0.2 \% \quad \mathrm{CeO}^{+} / \mathrm{Ce}^{+}$ ratio). Results are shown in Table 4.

All elements except Ag and Tl met the USEPA 75-125\% recovery for matrix spikes. Silver and thallium showed less than 80 percent recovery due to poor solubility in unacidified seawater. Relative Percent Difference (RPD) was calculated between the MS and MSD samples. USEPA 6020A requires the RPD to be less than $+/-20 \%$ for analytes whose concentration is greater than 100x the MDL. No elements failed the MS/MSD test. It is also noteworthy that while the $7700 \mathrm{x}$ is capable of quickly and accurately measuring trace elements in seawater, it was also able to measure the sodium concentration accurately, under the same analytical conditions and in the same run as all the other mineral and trace elements. The sodium concentration in $1 / 10$ seawater is $1180 \mathrm{ppm}$. The measured concentration, $1103 \mathrm{ppm}$ is $93 \%$ recovery, even though the highest calibration standard was only $200 \mathrm{ppm}$.

\subsection{Recovery of Certified Reference Values}

In addition to synthetic seawater spikes, 4 standard reference samples were analyzed repeatedly. They were NIST $1643 \mathrm{e}$ water (National Institute of Science and Technology (NIST), Gaithersburg MD), CRM River Sediment A, CRM Soil A, and CRM Soil B (High Purity 


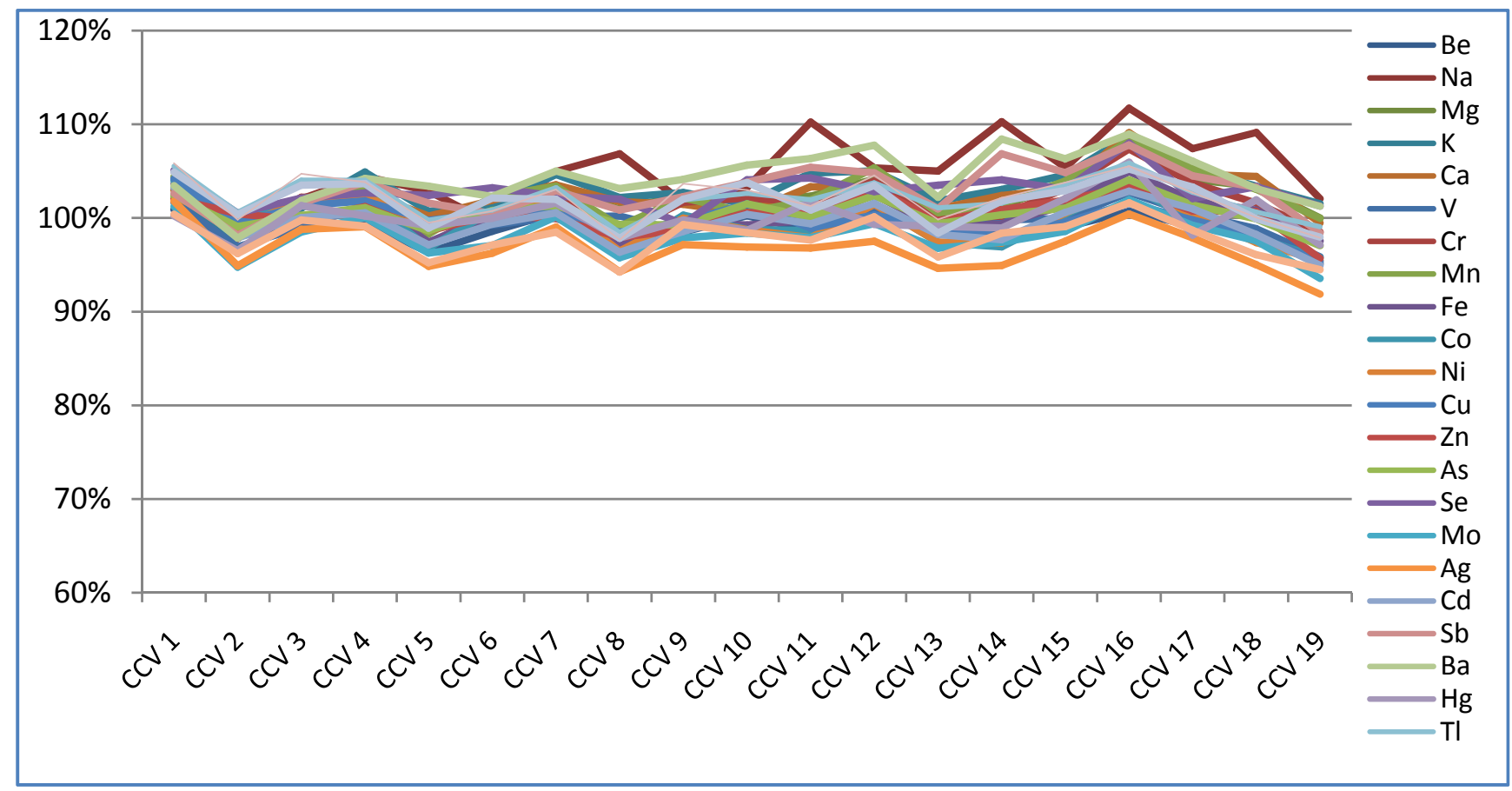

Fig. (5). Continuing Calibration Verification $(\mathrm{CCV})$ recoveries for periodic $\mathrm{CCV}$ samples for all analyte elements. USEPA limits for CCV recoveries are $\pm 10 \%$ of expected.

Table 4. Seawater (1/10 Dilution) Matrix Spike (MS) and Matrix Spike Duplicate (MSD) Results for All Analyte Elements. Mean and \% Relative Standard Deviation (\%RSD) and Mean Recovery of Spiked Value are Shown. RPD is the Relative Percent Difference Between the Mean MS and Mean MSD. USEPA Limits for RPD Between MS and MSD are $\pm 20 \%$

\begin{tabular}{|c|c|c|c|c|}
\hline Isotope/Element & Matrix Spike Mean $(n=10)$ & $\%$ RSD $(n=10)$ & Mean Recovery (\%) & RPD MS/MSD (\%) \\
\hline $9 \mathrm{Be}$ & 0.975 & 8 & 97 & 3.6 \\
\hline $24 \mathrm{Mg}$ & 96.1 & 2 & 91 & -0.7 \\
\hline $44 \mathrm{Ca}$ & 112.7 & 8 & 91 & -7.7 \\
\hline $51 \mathrm{~V}$ & 1.007 & 3 & 100 & -2.1 \\
\hline $55 \mathrm{Mn}$ & 1.112 & 4 & 111 & -7.6 \\
\hline $56 \mathrm{Fe}$ & 90.2 & 4 & 88 & -3.1 \\
\hline $59 \mathrm{Co}$ & 0.984 & 3 & 95 & -1.2 \\
\hline $60 \mathrm{Ni}$ & 0.997 & 3 & 95 & 4.3 \\
\hline $78 \mathrm{Se}$ & 1.555 & 11 & 104 & 0.3 \\
\hline $95 \mathrm{Mo}$ & 1.018 & 3 & 97 & 3.7 \\
\hline $107 \mathrm{Ag}$ & 0.642 & 6 & 61 & -14.1 \\
\hline $111 \mathrm{Cd}$ & 0.942 & 4 & 94 & 0.1 \\
\hline $121 \mathrm{Sb}$ & 1.048 & 4 & 103 & 1.6 \\
\hline $137 \mathrm{Ba}$ & 1.189 & 13 & 100 & 2.9 \\
\hline $205 \mathrm{Tl}$ & 0.719 & 3 & 66 & -14.9 \\
\hline $208 \mathrm{~Pb}$ & 1.264 & 17 & 108 & 0.0 \\
\hline $232 \mathrm{Th}$ & 0.862 & 2 & 86 & -4.2 \\
\hline
\end{tabular}




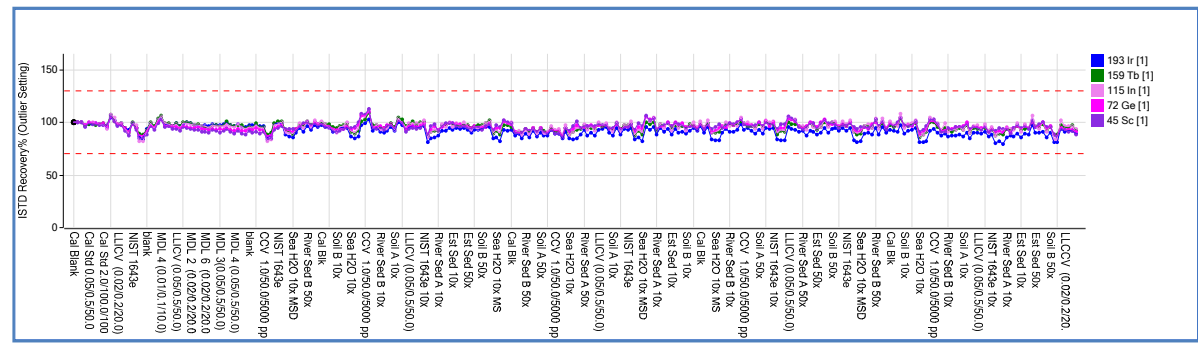

Fig. (6). Raw internal standard counts for 5 internal standards ( $\mathrm{Sc}, \mathrm{Ge}, \mathrm{In}, \mathrm{Tb}$, Ir) normalized to initial calibration blank in percent for all 275 samples measured. USEPA limits are $>70 \%$ (shown as lower dashed line). No USEPA upper limit is specified, though upper dashed line is $130 \%$.

Table 5. Mean Measured Values, Recoveries, Percent Relative Standard Deviations (\%RSDs) for All Certified Elements in the 4 Certified Reference Materials Analyzed. Blank Cells Indicate No Certified Value

\begin{tabular}{|c|c|c|c|c|c|c|c|c|c|c|c|c|}
\hline \multirow[b]{2}{*}{$\begin{array}{l}\text { Isotope/ } \\
\text { Element }\end{array}$} & \multicolumn{3}{|c|}{ NIST 1643e (n=12) } & \multicolumn{3}{|c|}{$\begin{array}{c}\text { CRM-River Sediment-A } \\
(\mathbf{n}=11)\end{array}$} & \multicolumn{3}{|c|}{ CRM-Soil-A $(n=11)$} & \multicolumn{3}{|c|}{ CRM-Soil-B $(\mathbf{n = 9})$} \\
\hline & $\begin{array}{l}\text { Mean } \\
\text { Conc } \\
(\text { ppb) }\end{array}$ & $\begin{array}{c}\text { RSD } \\
(\%)\end{array}$ & $\begin{array}{c}\text { Mean } \\
\text { Reco } \\
(\%)\end{array}$ & $\begin{array}{l}\text { Mean } \\
\text { Conc } \\
\text { (ppb) }\end{array}$ & $\begin{array}{l}\text { RSD } \\
(\%)\end{array}$ & $\begin{array}{c}\text { Mean } \\
\text { Reco } \\
(\%)\end{array}$ & $\begin{array}{l}\text { Mean } \\
\text { Conc } \\
(p p b)\end{array}$ & $\begin{array}{l}\text { RSD } \\
(\%)\end{array}$ & $\begin{array}{c}\text { Mean } \\
\operatorname{Reco}(\%)\end{array}$ & $\begin{array}{l}\text { Mean Conc } \\
\quad(\mathbf{p p b})\end{array}$ & $\begin{array}{l}\text { RSD } \\
(\%)\end{array}$ & $\begin{array}{c}\text { Mean } \\
\text { Reco } \\
(\%)\end{array}$ \\
\hline $9 \mathrm{Be}$ & 13.68 & 2.6 & 97.8 & 0.19 & 58.7 & & 0.14 & 92.7 & & 0.06 & 22.8 & \\
\hline $23 \mathrm{Na}$ & 20422 & 2.9 & 98.5 & 61068 & 10.2 & & 74158 & 1.4 & 105.9 & 101420 & 2.1 & 101.4 \\
\hline $27 \mathrm{Al}$ & 159.7 & 7.5 & 112.6 & 282730 & 2.1 & 113.1 & 531638 & 1.2 & 106.3 & 746683 & 2.3 & 106.7 \\
\hline $39 \mathrm{~K}$ & 2091 & 3.0 & 102.8 & 156789 & 2.2 & 104.5 & 201262 & 1.3 & 100.6 & 212065 & 2.3 & 101.0 \\
\hline $44 \mathrm{Ca}$ & 29456 & 2.9 & 91.2 & 292740 & 2.0 & 97.6 & 327451 & 1.2 & 93.6 & 118893 & 1.8 & 95.1 \\
\hline $51 \mathrm{~V}$ & 38.20 & 2.2 & 100.9 & 254.8 & 2.3 & 101.9 & 100.9 & 1.8 & 101.0 & 797.0 & 1.9 & 99.6 \\
\hline $52 \mathrm{Cr}$ & 20.81 & 2.6 & 102.0 & 320197 & 2.8 & 106.7 & 4.44 & 11.4 & & 396.5 & 2.0 & 99.1 \\
\hline $60 \mathrm{Ni}$ & 60.90 & 2.7 & 97.6 & 514.5 & 3.1 & 102.9 & 288.5 & 2.4 & 96.2 & 198.5 & 2.0 & 99.3 \\
\hline $63 \mathrm{Cu}$ & 22.25 & 2.1 & 97.8 & 1000 & 2.8 & 100.0 & 288.2 & 2.0 & 96.1 & 3165 & 1.5 & 105.5 \\
\hline $66 \mathrm{Zn}$ & 77.93 & 1.7 & 99.3 & 16496 & 2.3 & 110.0 & 984.7 & 1.7 & 98.5 & 73858 & 1.5 & 105.5 \\
\hline $75 \mathrm{As}$ & 60.06 & 2.1 & 99.4 & 617.1 & 2.0 & 102.8 & 202.9 & 1.5 & 101.4 & 6149 & 1.5 & 102.5 \\
\hline $78 \mathrm{Se}$ & 12.12 & 3.5 & 101.3 & 28.57 & 6.4 & & 12.76 & 11.8 & & 3.66 & 22.5 & \\
\hline 95 Мo & 119.30 & 2.2 & 98.3 & 0.81 & 13.8 & & 0.46 & 20.1 & & 0.51 & 16.0 & \\
\hline $107 \mathrm{Ag}$ & 0.64 & 13 & 60.0 & 1.26 & 29.2 & & 0.43 & 38.9 & & 0.64 & 14.5 & \\
\hline $111 \mathrm{Cd}$ & 6.38 & 2.8 & 97.2 & 102.3 & 2.4 & 102.3 & 0.19 & 21.7 & & 201.3 & 1.8 & 100.7 \\
\hline $121 \mathrm{Sb}$ & 59.04 & 2.8 & 101.3 & 535.6 & 1.9 & 107.1 & 32.09 & 2.3 & 107.0 & 430.4 & 2.8 & 107.6 \\
\hline
\end{tabular}

Standards - Charleston SC, USA). NIST 1643e was analyzed undiluted, while the other reference materials were analyzed after both 10x and 50x dilutions. Values shown in Table 5 were taken from the 10x dilutions. Each sample was measured multiple times over the sequence and the mean concentration, $\%$ relative standard deviation ( $\%$ RSD), and mean recovery were calculated for each analyte - Table $\mathbf{5}$. Not all reference materials are certified for all analytes blank cells indicate no certified value.

\section{CONCLUSIONS}

Significant improvements in the productivity of ICP-MS analysis of environmental samples are possible. However, simply shortening the run time alone is not sufficient. In order to achieve truly high productivity, the ICP-MS must be capable of maintaining a high rate of sample analysis (short run times) for an extended period without QC failures or the need for operator intervention. By combining discrete 
sampling to reduce uptake, stabilization and rinseout time with helium collision mode to reduce measurement time, and aerosol dilution to improve matrix tolerance and long term stability; average run-to-run times for long sequences of complex environmental samples can be reduced to less than 2 minutes, while meeting USEPA criteria for data quality.

\section{REFERENCES}

[1] Direct Analysis of Undiluted Soil Digests Using the Agilent High Matrix Introduction Accessory with the 7500cx ICP-MS. Agilent Technologies Application Note 5989-7929EN, 2009

[2] Direct Analysis of Undiluted Seawater by ICP-MS Using a Novel High Matrix Introduction System. http://spectroscopyonline.findan alytichem.com/spectroscopy/data/articlestandard/spectroscopy/122 008/504351/article.pdf [accessed March 8, 2010].

[3] A Comparison of the Relative Cost and Productivity of Traditional Metals Analysis Techniques versus ICP-MS in High Throughput Commercial Laboratories. Agilent Technologies Application Note 5989-1585EN, 2009.
[4] Rodriguez, I.B.; Francesconi, K.A.; Goessler, W. A rapid method for the determination of total arsenic in biological digests and aqueous extracts by flow injection inductively coupled plasma mass spectrometry. J. Anal. At. Spectrom., 2008, 2, 235-239.

[5] Amplifying ICP-MS Productivity using Discrete Sampling Technology - Agilent Technologies e-seminar http://cp.chem.agile nt.com/Library/slide presentation/Public/Amplifying\%20ICPMS\% 20Productivity\%20using\%20Discrete\%20Sampling\%20Technolog y\%20finalV̈032609.pdf [accessed March 5, 2010].

[6] McCurdy, E.; Woods, G. The application of collision/reaction cell inductively coupled plasma mass spectrometry to multi-element analysis in variable sample matrices, using $\mathrm{He}$ as a non-reactive cell gas J. Anal. At. Spectrom., 2004, 5, 607-615.

[7] Darrouzès, J.; Bueno, M.; Lespès, G.; Potin-Gautier, M. Operational optimisation of ICP-octopole collision/reaction cell-MS for applications to ultratrace selenium total and speciation determination. J. Anal. At. Spectrom., 2005, 2, 88-94.

[8] Wilbur, S. A pragmatic approach to managing interferences in ICPMS. Spectroscopy, May 1, 2008.

[9] Wilbur, S. Factors determining sensitivity in ICP-MS spectroscopy Spectroscopy-Applications of ICP and ICP-MS, Nov, 2009, 10. 